$\Phi=\Phi$

\title{
Determinants of demand for subsequent doses of pneumococcal and rotavirus vaccines for children less than five years of age in Ghana
}

\author{
Mustapha Immurana ${ }^{1 *}$, Arabi $\mathbf{U}^{2}$ \\ ${ }^{1}$ Research Scholar, Department of Economics, Mangalore University, Mangalagangotri - 574119, Karnataka State, India \\ ${ }^{2}$ Professor and Research Guide, Department of Economics, Mangalore University, Mangalagangotri - 574119, Karnataka State, India \\ *Corresponding author E-mail: mustaphaimmurana@gmail.com
}

\begin{abstract}
The mortality of children which has pneumonia and diarrhoea as some of its major causes remains a major concern for all countries of which Ghana is no exception. Ghana's current child mortality rate is far above the sustainable development goal 3.2. However, given that vaccination is one of the most effective ways of preventing childhood diseases, it was surprising that, the 2014 Ghana demographic and health survey (GDHS) report showed a falling up-take or coverage in the successive doses of the pneumococcal (pneumonia vaccine) and rotavirus (diarrhoea vaccine) vaccines among children in Ghana. This study therefore using data from the children's recode file of the 2014 GDHS, investigated the determinants of demand for subsequent doses of the pneumococcal and rotavirus vaccines for children in Ghana by employing the binary probit model. The study among other findings revealed that, unemployed mothers were less likely to demand for the subsequent and initial doses of both the pneumococcal and rotavirus vaccines for their children. Also male hou sehold heads were revealed to be less likely to demand for all the doses of the rotavirus vaccines for children. In addition, single mothers were also revealed to be less likely to demand for all the subsequent doses of the pneumococcal and rotavirus vaccines. Therefore targeting unemployed and single mothers as well as women empowerment through job opportunities coupled with public education, especially of household heads, would serve as effective tools in tackling the falling demand for subsequent doses of the pneumococcal and rotavirus vaccines for children in Ghana.
\end{abstract}

Keywords: Child Health; Demand; Pneumococcal Vaccine; Rotavirus Vaccine; Ghana.

\section{Introduction}

One of the major public health concerns globally, is the issue of child health. Aside the fact that children all over the world have the right to live, it is also worth noting that, they form an integral part of human capital since they are expected to grow and replace the older generation. Therefore it is not surprising that the sustainable development goal (SDG) 3.2 (which replaced the Millennium development goal (MDG) 4) is geared towards reducing the mortality of children less than five years of age. Thus international partners and individual countries have been instituting measures towards reducing child mortality.

However, even though the mortality of children has seen some reduction, approximately 6 million children died in 2015 mostly from preventable causes with almost half of these deaths occurring in Sub-Saharan Africa. It is further predicted that, lots of children will die from preventable causes such as pneumonia and diarrhoea (UN, 2015).

According to UNICEF (2012), pneumonia and diarrhoea are responsible for closely $29 \%$ of the mortalities in children less than five years of age leading to over two million deaths annually in the world. Further, Diarrhoea alone is estimated to cause more than 1.5 million deaths in children less than five years annually and most of these deaths happen in sub-Saharan Africa and South Asia. Diarrhoea is a serious killer of children less than five years of age killing more than measles, AIDS and malaria put together
(UNICEF/WHO, 2009). However one of the most effective ways of preventing pneumonia and diarrhoea is through the pneumococcal and rotavirus vaccines respectively.

Ghana (a sub-Saharan African country) as one of the signatories of MDG 4 and now SDG 3.2 has made several efforts which include the expanded immunization programme, which has the sole aim of getting all children vaccinated against all the major killer diseases. Thus with regards to the pneumococcal and rotavirus vaccines, children in Ghana are expected to receive all the three doses of the pneumococcal vaccine (pneumococcal 1, pneumococcal 2 and pneumococcal 3 vaccines) as well as all the two doses of the rotavirus vaccines (rotavirus 1 and rotavirus 2 vaccines) in order to be fully protected against these diseases.

However, recent report from the 2014 Ghana Demographic and Health Survey (GDHS) states that, there has been a fall in immunization coverage for children aged 12-23 months from $79 \%$ in 2008 to $77 \%$ in 2014 as well as a fall in the coverage of the successive or subsequent doses of pneumococcal and rotavirus vaccines (Ghana Statistical Service [GSS], Ghana Health Service [GHS] \& ICF International, 2015).

In addition, the 2014 GDHS puts the under-5 mortality rate in Ghana at 60 deaths per thousand live births, which implies that out of every 17 Ghanaian Children, 1 does not live up to age 5 (GSS, GHS, \& ICF International, 2015), which is far above the SDG 3.2 target of 25 deaths per 1000 live births by 2030 .

Thus given the fact that the 2014 Family Health Annual Report stated that, under five deaths in Ghana due to pneumonia and diar- 
rhoea have increased significantly over the 2012-2013 period (GHS, n.d.), with pneumonia being responsible for 20 Percent of the mortality and morbidity of children less than five years in Ghana according to a GHS report (2010, as cited in United Nations Development Programme [UNDP] \& Government of Ghana [GOG] / National Development Planning Authority [NDPA], 2015), it was imperative that a study is conducted to investigate the factors that determine the demand for the subsequent doses of the pneumococcal and the rotavirus vaccines among children in Ghana. Thus, helping in bringing out the factors that affect the uptake of the subsequent doses of these vaccines for children less than five years of age in Ghana, which would help in churning out policies that would aid in reducing the mortality of children in Ghana.

\section{Review of literature}

The literature on the demand for health stems from the works of Grossman (1972a, 1972b, 1999, 2000). Grossman contends that there is a derived demand for health and as such we consume health inputs viz., medicine, vaccines, embarking on regular physical exercise and avoiding smoking e.t.c not for their own sake but for the sake of gaining good health. As such, individuals are the producers of health (Grossman 1999, 2000). Thus from this, since children are not old enough to seek care for themselves, it means mothers or caregivers of children would basically demand for vaccines on behalf of their children, not for the sake of the vaccines themselves but with the intention of producing a better health in children.

On the empirical front with regards to the determinants of immunization or vaccine utilization, Russo et al. (2015) found in Dschang of Cameroon that, less usage of antenatal care by mothers, immunization card retention, child being the third or beyond with regards to birth order, younger mother's age, poor parental information on vaccination as well as poor parental attitude towards immunization are the major factors affecting incomplete immunization among children aged 12-23 months. Lakew et al (2015) found that, mother being in the rich wealth index, mothers being aware of community conversation programme, getting postnatal check-up within 2 months after birth, and sources of information from vaccination cards were the determinants of full immunization among children aged 12-23 months in Ethiopia. Cockcroft et al. (2014) found in Nigeria that mothers education, having birth certificates, discussion of immunization at home and mother's thinking of immunization as important were associated with the probability that a child aged 12-23 months received measles vaccination. Otieno et al. (2014) found that, older child and maternal age, hospitalizing a sibling in the past year, lesser distance from the immunization centre and having an occupation that did not restrict household administrator's to be away from home, were greatly associated with the probability of increased influenza vaccination up take among children in Kenya. Ibnouf et al. (2007) revealed that, vaccination rate of children under age five increased with a rise in mother's education and child's age in Khartoum (Sudan). Further, the study revealed strong association between children vaccination status and mother's knowledge and attitude towards vaccination whiles the probability of children getting the right vaccination was found to increase with a rise in mother's age. Logullo et al. (2008) found that, age, region, education and marital status were not related with taking measles vaccines adequately in Sao Paulo city of Brazil.

Specifically on Ghana, Dwumoh et al. (2014) using data from the 2011 Ghana Multiple Indicator Cluster Survey found that mother's education, National Health Insurance Scheme (NHIS) membership of children and geographical location influenced full immunization of children. McGlynn (2012) found in Ghana that antenatal care increased the odds of immunization among children in Ghana using the 1998, 2003, and 2008 GDHS. Duah-Owusu (n.d.) revealed that, using the national sample, the classical determinants of health (for example occupation, wealth and education) and the alternative social determinants of health (for example drinking water and owning a radio set) were associated with full immunization with a health card. Matthews and Diamond (1997) found the education of women, region and the type of prenatal care mother received as essential determinants of immunization among children less than five years of age in Ghana using the 1988 GDHS. Bosu et al. (1997) found waiting time, transportation difficulties, lack of appropriate venues and furniture at outreach clinics, weak inter sectoral collaboration, poor knowledge on immunization, financial challenges and ill- motivated service providers, as the major factors deterring immunization visits in the Komenda-Edina-Eguafo-Abrem District of Ghana.

However, among the papers revealed, specifically those on Ghana, none of them studied the determinants of utilization of individual vaccines let alone the up-take of the subsequent doses of vaccines which is essential in unravelling the factors that are responsible for the falling up-take of the successive doses of the pneumococcal and rotavirus vaccines as reported in the 2014 GDHS.

Thus to the best of the authors knowledge, this study is the first of its kind to study the determinants of utilization or demand for the initial and subsequent doses of the pneumococcal and rotavirus vaccines among children less than five years of age in Ghana.

In addition, this paper utilized the most current national demographic and health survey (2014 GDHS) which is more current than all those used by the previous studies on Ghana.

\section{Methodology}

\subsection{Data source}

The main source of data for the study was from the children's recode file of the 2014 GDHS (a cross sectional survey carried out from early September to mid-December 2014) which contained information on 5884 children less than five years with regards to their immunization status, feeding practices, mother's information, other household features e.t.c. The 2014 GDHS was carried out by the Ghana health Service, the Ghana Statistical Service and other partners. It must further be stated that, the 2014 GDHS, is the most current nationally representative demographic and health survey on Ghana.

\subsection{Empirical model and variable description}

The theoretical basis of the study stemmed from the Grossman model of demand for health which basically assumes that individuals maximise the utility they obtain from the consumption of health inputs and other goods subject to some constraint. Therefore since children are not old enough to make decisions on their health, mothers or care givers are assumed to utilise vaccines for children based on their expected utility. That is if mothers or caregivers expected utility of a child being vaccinated (1) is greater than not being vaccinated $(0)$, the child would get vaccinated and vice versa. Therefore we specified a simple demand function for a particular vaccine as follows:

$$
\mathrm{K}=\mho \mathrm{M}+\Omega \mathrm{C}+\Phi \mathrm{S}+\mu
$$

Where $\mathrm{K}$ is the dependent variable, which represents the probability that a mother would demand a particular dose of a vaccine for the child or not. Thus $\mathrm{K}$ was coded as 1 if child received a particular dose of a vaccine and 0 if child did not receive. It must be stressed that each dose of a vaccine in this case becomes a dependent variable. $\mathrm{M}$ is maternal and partner's features such as education, age, employment e.t.c, $\mathrm{C}$ represents child features such as age, sex and birth order and $\mathrm{S}$ represents other socio-economic factors such as household wealth status, region, residence type, 
ethnicity e.t.c., $\mho, \Omega$, and $\Phi$ are vector of parameters of the independent variables and $\mu$ is the error term.

Aside Mother's age, age of the household head, birth order of the child and child's age that were continuous variables, all the other remaining variables were categorical. Therefore these categorical variables were turned in to dummy variables using the factor variable approach. The authors wish to state that, mother's marital status, wealth status, religion were recoded from how they were in the original data to their present nature as used in this study. With regards to the dependent variables, viz., doses of pneumococcal and rotavirus vaccine, if a vaccine was ticked on a child's card, or date when vaccine was given was found on the card or if mother gave a correct verbal response as to the nature of a vaccine that it has been given to a child, it was coded as 1(Yes) and if otherwise $(0)$. Thus since the dependent variables were dichotomous, the study employed the Probit model to examine the determinants of demand for the doses of the pneumococcal and rotavirus vaccines. The authors wish to state that all don't know responses found in the data were treated as missing values. Thus the existence of missing values could lead to observation for some variables not to be up to 5884. Since Williams (2012) contends that marginal effects are one of the famous approaches to give more intuitive meaning to variables in nonlinear models like probit, the study reported the Average marginal effects (AMEs) of the variables. The AME was used because according to Williams (2012), many researchers see it to be superior to the Marginal effects at the means (MEMs).

\section{Results and discussion}

\subsection{Descriptive statistics}

This section tackled the socio-economic, geographic and demographic information of children, their mothers and partner's information. As can be seen in Table 1 below, among the 5884 sampled mothers/children, majority of them (902) constituting 15.33 Percent were from the northern region followed by the Brong Ahafo region with 653 making up 11.10 Percent whilst the leas number of respondents (460) were from the Greater Accra region which constituted 7.82 Percent. Also Majority of the mothers/children $(60.16 \%)$ were from the rural areas with $39.84 \%$ from urban areas. On religion, majority of the respondents constituting $71.02 \%$ were Christians followed by Islam which constituted $20.46 \%$ and Traditional/spiritual or no religion (Traditional) which constituted $8.51 \%$. With regards to ethnicity, majority viz., 2,244 $(38.14 \%)$ of the respondents were Akans, followed by MoleDagbani with $1,557(26.47 \%)$ and the Mande ethnicity had the least number of respondents $(87(1.48 \%))$. Among the sampled mothers, $34.70 \%(2,042)$ were uneducated, $20.55 \%(1,209)$ had primary education, $40.94 \%(2,409)$ had secondary education and $3.81 \%$ (224) had higher education. Thus majority of mothers were educated with most of them having secondary education which sends a good signal with regards to child health utilisation. With regards to the health insurance status of mother's, $69.47 \%$ of them had health insurance whiles $30.53 \%$ of them were uninsured. Thus still some mothers in Ghana are yet to be enrolled on any health insurance scheme even though there is a free registration for pregnant women on the National Health Insurance Scheme. Also $66.59 \%$ of mothers were married with $33.41 \%$ being single. On mothers' employment, $20.70 \%(1,217)$ of them were unemployed whiles $79.30 \%(4,663)$ were employed. Thus majority of the sampled mothers were employed signifying better affordability of child health utilisation. Also $6.71 \%, 48.73 \%$ and $32.09 \%$ of the sampled mothers felt that getting permission, money and distance (to health facility) to seek medical care or help for themselves, respectively, were big problems. On partner's education, $30.83 \%$ $(1,667)$ were uneducated, $12.13 \%(656)$ had primary education, $47.99 \%(2,595)$ had secondary education and $9.04 \%$ (489) had higher education. Thus majority of them had secondary education, similar to the case of mothers. Further, male household heads constituted $76.43 \%$, male children constituted $52.11 \%$ and Nonrich households constituted $72.62 \%$ of respondents.

Also in Table 2 below, out of the 5, 515 children, the percentage who received the first dose of the pneumococcal vaccine constituted 63.14 Percent, which reduced to 58.10 Percent when it came to the second dose and further reduced to 50.59 Percent, when it came to the third dose. This is very worrying and hence the need for an investigation in to the factors that are responsible for the fall in the demand for the successive doses of the Pneumococcal vaccine. Similar observation was found in Table 2 where out of the 5,504 children, the percentage who received the first dose of the rotavirus vaccine comprised 60.65 Percent which reduced to 55.20 Percent when it came to the second dose and hence the need for an investigation in to these causative factors. It can also be seen in Table 2 that, the mean ages of mothers, household heads, and children were $30.6 y e a r s, 40.2$ years and 1.9 years respectively with the mean birth order of children being 3.3.

Table 1: Socio-Economic, Demographic and Geographical Background of Respondents

\begin{tabular}{|c|c|c|c|c|c|c|c|c|}
\hline Variable & Frequency & $(\%)$ & Variable & Frequency & $(\%)$ & Variable(continued) & Freq. & $(\%)$ \\
\hline Region & $\mathrm{N}=5,884$ & 100.00 & $\begin{array}{l}\text { Mother's Educa- } \\
\text { tion }\end{array}$ & $\mathrm{N}=5,884$ & 100.0 & Primary & 656 & 12.13 \\
\hline Western & 582 & 9.89 & No education & 2,042 & 34.70 & Secondary & 2,595 & 47.99 \\
\hline Central & 603 & 10.25 & Primary & 1,209 & 20.55 & Higher & 489 & 9.04 \\
\hline Greater Accra & 460 & 7.82 & Secondary & 2,409 & 40.94 & Sex of Household head & $\mathrm{N}=5,884$ & 100.0 \\
\hline Volta & 481 & 8.17 & Higher & 224 & 3.81 & Male & 4,497 & 76.43 \\
\hline Eastern & 545 & 9.26 & $\begin{array}{l}\text { Mother's Insur- } \\
\text { ance }\end{array}$ & $\mathrm{N}=5,883$ & 100.0 & Female & 1,387 & 23.57 \\
\hline Ashanti & 599 & 10.18 & Insured & 4,087 & 69.47 & Sex of the child & $\mathrm{N}=5,884$ & 100.0 \\
\hline Brong Ahafo & 653 & 11.10 & Uninsured & 1,796 & 30.53 & Male & 3,066 & 52.11 \\
\hline Northern & 902 & 15.33 & $\begin{array}{l}\text { Marital Sta- } \\
\text { tus(Mother) }\end{array}$ & $\mathrm{N}=5,884$ & 100.0 & Female & 2,818 & 47.89 \\
\hline Upper East & 551 & 9.36 & Married & 3,918 & 66.59 & Wealth Status & $\mathrm{N}=5,884$ & 100.0 \\
\hline Upper West & 508 & 8.63 & Single & 1,966 & 33.41 & Rich & 1,611 & 27.38 \\
\hline Religion & $\mathrm{N}=5,884$ & 100.00 & $\begin{array}{l}\text { Mother's Em- } \\
\text { ployment }\end{array}$ & $\mathrm{N}=5880$ & 100.0 & Non-Rich & 4,273 & 72.62 \\
\hline Christian & 4,179 & 71.02 & Employed & 4,663 & 79.30 & Residence & $\mathrm{N}=5,884$ & 100.0 \\
\hline Islam & 1,204 & 20.46 & $\begin{array}{l}\text { Unemployed } \\
\text { Permission to seek }\end{array}$ & 1,217 & 20.70 & Urban & 2,344 & 39.84 \\
\hline Traditional & 501 & 8.51 & $\begin{array}{l}\text { Medical care by } \\
\text { mother }\end{array}$ & $\mathrm{N}=5,883$ & 100.0 & Rural & 3,540 & 60.16 \\
\hline Ethnicity & $\mathrm{N}=5,883$ & 100.0 & Big Problem & 395 & 6.71 & & & \\
\hline Akan & 2,244 & 38.14 & $\begin{array}{l}\text { Not a big problem } \\
\text { Money to seek }\end{array}$ & 5,488 & 93.29 & & & \\
\hline $\mathrm{Ga} /$ Dangme & 261 & 4.44 & $\begin{array}{l}\text { medical care by } \\
\text { mother }\end{array}$ & $\mathrm{N}=5,883$ & 100.0 & & & \\
\hline
\end{tabular}




\begin{tabular}{|c|c|c|c|c|c|}
\hline Ewe & 654 & 11.12 & Big Problem & 2,867 & 48.73 \\
\hline Guan & 145 & 2.46 & Not a big problem & 3,016 & 51.27 \\
\hline Mole-Dagbani & 1,557 & 26.47 & $\begin{array}{l}\text { Distance to seek } \\
\text { medical care by } \\
\text { mother }\end{array}$ & $\mathrm{N}=5,883$ & 100.0 \\
\hline Grusi & 246 & 4.18 & Big problem & 1,888 & 32.09 \\
\hline Gurma & 578 & 9.82 & Not a big problem & 3,995 & 67.91 \\
\hline Mande & 87 & 1.48 & $\begin{array}{l}\text { Partner's Educa- } \\
\text { tion }\end{array}$ & $\mathrm{N}=5,407$ & 100.0 \\
\hline Other & 111 & 1.89 & No Education & 1,667 & 30.83 \\
\hline
\end{tabular}

Source: Authors unweighted computation from the children's recode file, 2014 GDHS

Table 2: Descriptive Statistics of Vaccine Up-Take and Continuous Variables

\begin{tabular}{|c|c|c|c|c|c|c|c|}
\hline Vaccine Uptake & Frequency & $\%$ & Variable & Observation & Mean & Min. Value & Max. Value \\
\hline Pneumococcal 1 & & & Mother's Age & 5,884 & 30.60061 & 15 & 49 \\
\hline No & 2,033 & 36.86 & Age of Household Head & 5,884 & 40.16366 & 16 & 95 \\
\hline Yes & 3,482 & 63.14 & Child's Birth Order & 5,884 & 3.349422 & 1 & 13 \\
\hline Total & 5,515 & 100.0 & Child's Age (years) & 5,595 & 1.933512 & 0 & 4 \\
\hline \multicolumn{8}{|l|}{ Pneumococcal 2} \\
\hline No & 2,311 & 41.90 & & & & & \\
\hline Yes & 3,204 & 58.10 & & & & & \\
\hline Total & 5,515 & 100.0 & & & & & \\
\hline \multicolumn{8}{|l|}{ Pneumococcal 3} \\
\hline No & 2,725 & 49.41 & & & & & \\
\hline Yes & 2,790 & 50.59 & & & & & \\
\hline Total & 5,515 & 100.0 & & & & & \\
\hline \multicolumn{8}{|l|}{ Rotavirus 1} \\
\hline No & 2,166 & 39.35 & & & & & \\
\hline Yes & 3,338 & 60.65 & & & & & \\
\hline Total & 5,504 & 100.0 & & & & & \\
\hline \multicolumn{8}{|l|}{ Rotavirus 2} \\
\hline No & 2,466 & 44.80 & & & & & \\
\hline Yes & 3,038 & 55.20 & & & & & \\
\hline Total & 5,504 & 100.0 & & & & & \\
\hline
\end{tabular}

Source: Authors unweighted computation from the children's recode file, 2014 GDHS

\subsection{Empirical model results}

Table 3: Probit Regressions on Determinants of Demand for Pneumococcal Vaccines

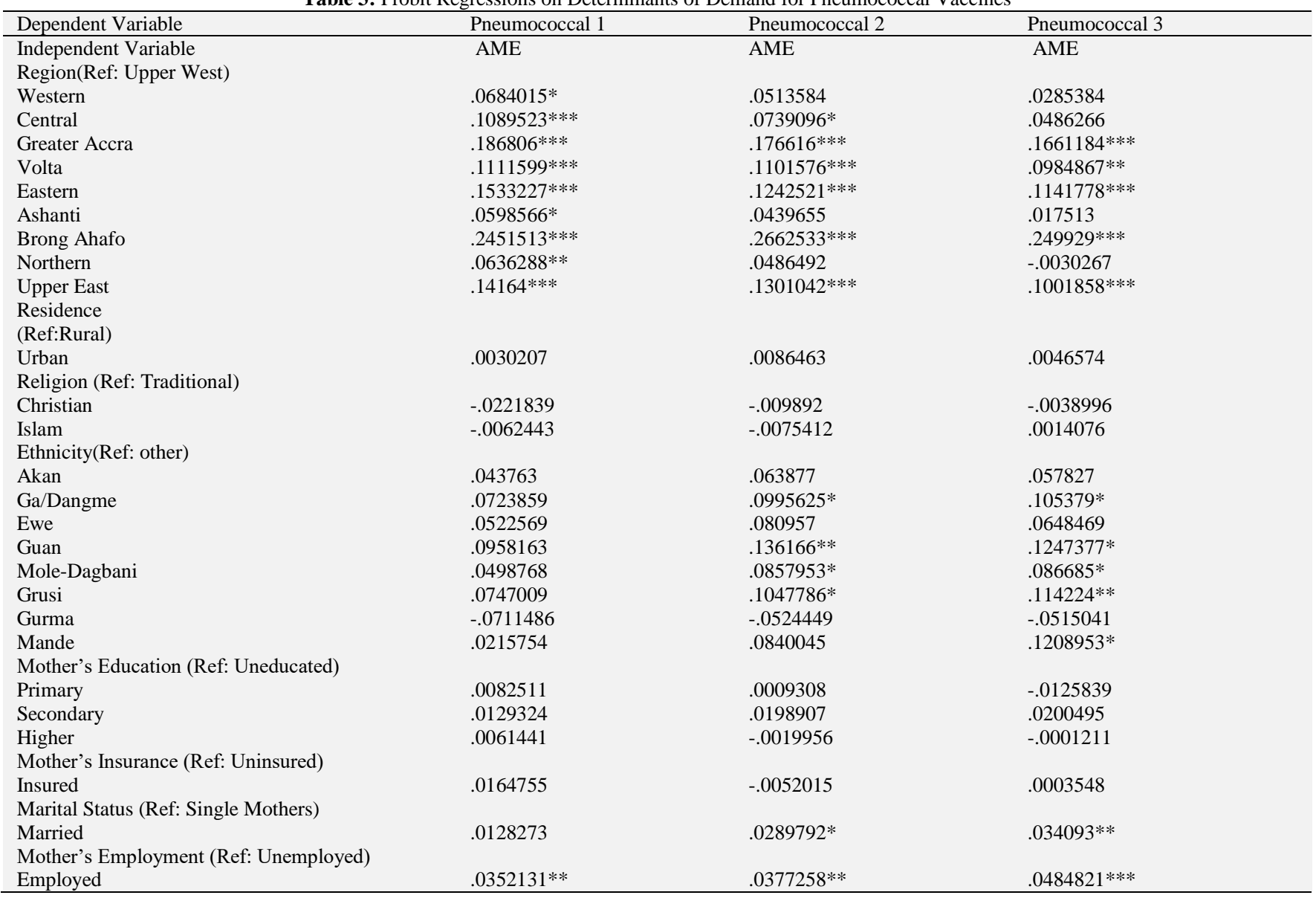




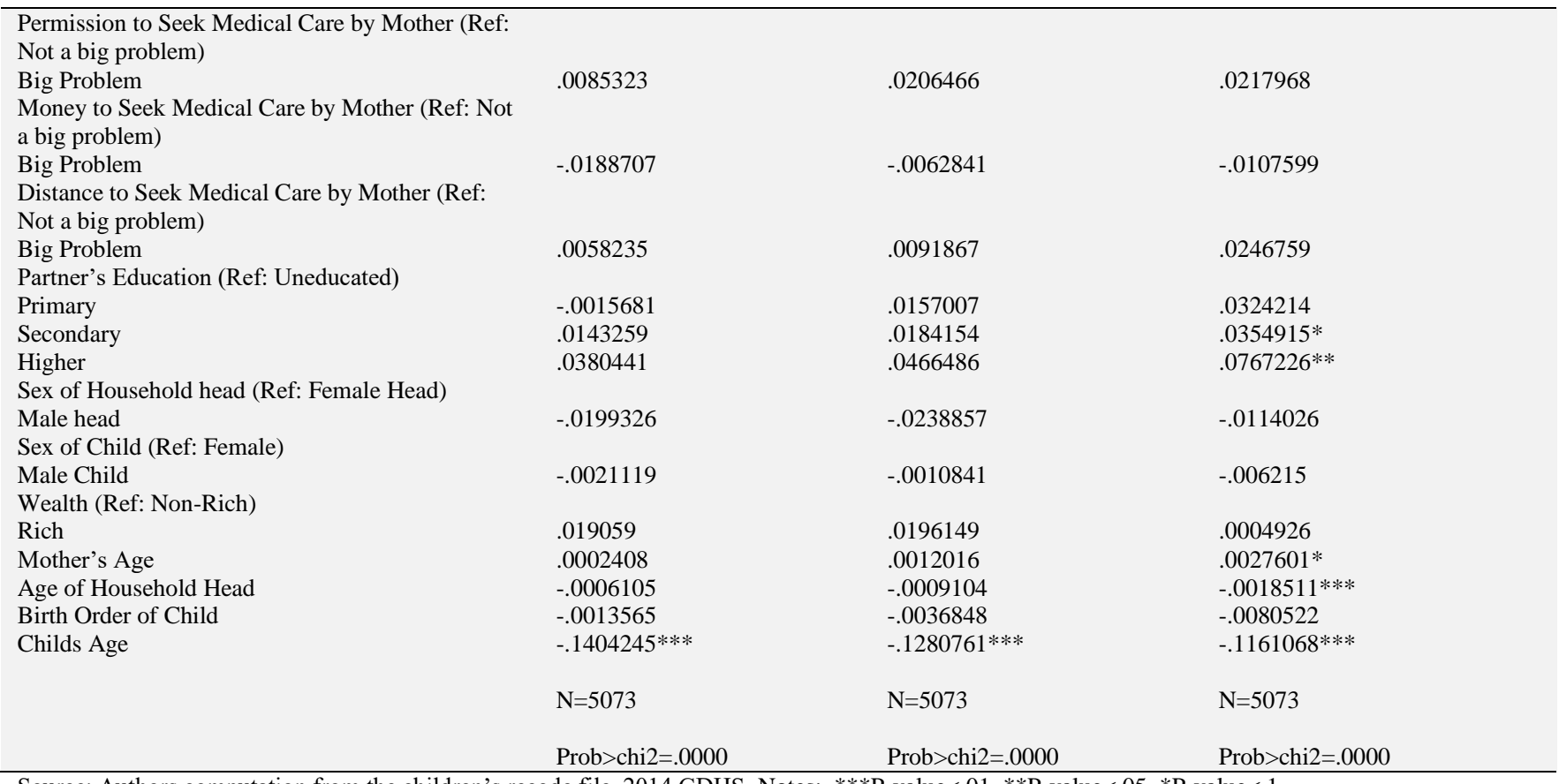

Source: Authors computation from the children's recode file, 2014 GDHS. Notes: ***P-value<.01, **P-value<.05, *P-value<.1

The authors wish to state that, the analysis on the empirical results was based on the AMEs of the variables and also when children are stated to have received or demanded a vaccine, it must be kept in mind that the actual demand was made on their behalf by their caregivers or mothers.

The results on the determinants of demand for Pneumococcal 1 vaccine as shown in Table 3 revealed that all the regions had positive AMEs which were significant at $1 \%$ with only Western and Eastern being significant at $10 \%$ and Northern at $5 \%$. Thus on average, children in the Upper East, Ashanti, Northern, Brong Ahafo, Eastern, Volta, Greater Accra, Western and Central regions were $14 \%, 6 \%, 6 \%, 25 \%, 15 \%, 11 \%, 19 \%, 7 \%$ and $11 \%$ respectively more likely to have received the Pneumococcal 1 vaccine relative to those in the Upper West region (reference region). Thus mothers in these regions were more probable to demand for Pneumococcal 1 vaccine for their children as compared to those mothers from the Upper west region. Also, employed mothers had a positive significant (at 5\%) AME, and thus on average, children of employed mothers were $4 \%$ more likely to have received the Pneumococcal 1 vaccine as compared with children with unemployed mothers. Further, as the age of children increased by a year on average, it decreased the likelihood that they will receive the Pneumococcal 1 vaccine by $14 \%$. Thus older children were less likely to have received the Pneumococcal 1 vaccine. This could be that since the pneumococcal vaccine was introduced in 2012, older children might have been old enough to receive the $1^{\text {st }}$ dose at the recommended age of 6 weeks and hence mothers did not utilise for them.

With regards to the Pneumococcal 2 vaccine, on average, children from the Greater Accra, Central, Eastern, Volta, Upper East and Brong Ahafo regions, were respectively $18 \%, 7 \%, 12 \%, 11 \%$, $13 \%$ and $27 \%$ more likely to have received the Pneumococcal 2 vaccine relative to children in the Upper west region since all their AMEs were significant at $1 \%$ except Central which was significant at $10 \%$. Further, children with Guan, Ga/Dangme, Grusi and Mole-Dagbani backgrounds were respectively 14\%, 10\%, $10 \%$ and $9 \%$ more probable to have received the Pneumococcal 2 vaccine relative to those from the other ethnic groups (reference group). Thus ethnicity and region of residence influenced the demand for the Pneumococcal 2 vaccine for children in Ghana. Further results show that, children with employed and married mothers on average were $4 \%$ and $3 \%$ respectively more likely to have received the pneumococcal 2 vaccine relative to those with unemployed and single mothers. Thus marital status of the mother as well her employment, greatly determined her demand for the pneumococcal 2 vaccine for her child. This is not surprising because even though these vaccines are normally free of charge, employed mothers and married mothers (with the support of their husbands) are more capable of affording any indirect cost of vaccines (for example cost of transportation to vaccination centres) relative to their unemployed and single counterparts respectively. Also it could be that employed mothers value their time very well and would not want to waste lots of productive hours or days in seeking for medical treatment for their children and hence would be more willing to adopt preventive measures (vaccination) which only last for some few hours in a day. Also on average, as the age of children increased by a year, it reduced, the probability that they will receive the Pneumococcal 2 vaccine by $13 \%$ given the significant (at 1\%) AME of -.1280761. Thus as children get older as found under the Pneumococcal 1 vaccine, mothers reduced the demand for the Pneumococcal 2 vaccine for them. This could be attributed to the thinking of some mothers that older children are less susceptible to diseases which is worrying since so far as they are still under five years they are vulnerable to pneumonia. Also it could be that since the pneumococcal vaccine was introduced in 2012 , older children might have been old enough to receive the $2^{\text {nd }}$ dose at the recommended age of 10 weeks and hence mothers did not utilise for them.

Moreover, the results on the determinants of demand for Pneumococcal 3 vaccine showed that, on average, children from the Volta, Greater Accra, Eastern, Upper East and Brong Ahafo regions, were $10 \%, 17 \%, 11 \%, 10 \%$, and $25 \%$ respectively more probable to have received the Pneumococcal 3 vaccine as compared with children in the Upper west region. Thus the region of residence, greatly influenced mothers demand for the pneumococcal 3 vaccine for children. Also on the average, children with Guan, $\mathrm{Ga} /$ Dangme, Mole-Dagbani, Mande and Grusi backgrounds were $12 \%, 11 \%, 9 \%, 12 \%$ and $11 \%$ respectively more likely to have received the Pneumococcal 3 vaccine as compared with children from the other ethnic groups. Thus mothers/care givers of such ethnic groups were more likely to demand for the pneumococcal 3 vaccine for their children. Further, employed and married mothers were respectively $5 \%$ and $3 \%$ more likely to have utilised the pneumococcal 3 vaccine for their children as compared with children with unemployed and single mothers. Thus being a married or an employed mother increased the demand for the Pneumococcal 3 for vaccine for children. The explanation given above under the Pneumococcal 2 vaccine still holds here.

Also, children whose mothers had Partners with Higher and Secondary education were $8 \%$ and $4 \%$ respectively more likely to 
have received the Pneumococcal 3 vaccine relative to those whose mothers had uneducated partners. Thus educated partners are well placed to better understand the essence of these subsequent doses to the health of children relative to their uneducated counterparts. Further, on average, an increase in mother's age by a year increased the likelihood that children received the pneumococcal 3 vaccine by $.3 \%$. Thus rising mothers age, increased the demand for the pneumococcal 3 vaccine for children. This can be explained by the fact older mothers might have gained so much experience from their previous births on the essence of this subsequent dose and hence would be more willing to utilise it for their children relative to younger mothers.

Finally on the demand for pneumococcal 3, averagely, as the age of the child and that of the household head increased by a year, the probability that children received the Pneumococcal 3 vaccine fell by $12 \%$ and $.2 \%$ respectively. Thus rising ages of the child and household head, decreased the demand for the pneumococcal 3 vaccine for children. The result with regards to the age of the household head can be explained by the seeming negative perceptions some older people have about modern medicine or what they refer to as "doctor drugs." The result on age of the child could be that, since the pneumococcal vaccine was introduced in 2012, older children might have been old enough to receive the $3^{\text {rd }}$ dose at the recommended age of 14 weeks and hence mothers did not utilise for them.

Table 4: Probit Regressions on Determinants of Demand for Rotavirus Vaccines

\begin{tabular}{|c|c|c|}
\hline Dependent Variable & Rotavirus 1 & Rotavirus 2 \\
\hline Independent Variable & AME & AME \\
\hline \multicolumn{3}{|l|}{ Region(Ref: Upper West) } \\
\hline Western & .0466197 & .0423457 \\
\hline Central & $.0748115 * *$ & .0565543 \\
\hline Greater Accra & $.1861382 * * *$ & $.1996923 * * *$ \\
\hline Volta & $.1165443 * * *$ & $.0955377 * *$ \\
\hline Eastern & $.1089461 * * *$ & $.10419 * * *$ \\
\hline Ashanti & .0476341 & .0290849 \\
\hline Brong Ahafo & $.2426113 * * *$ & $.262451 * * *$ \\
\hline Northern & .0299585 & .0334737 \\
\hline Upper East & $.1214355^{* * * *}$ & $.115512 * * *$ \\
\hline \multicolumn{3}{|l|}{ Residence } \\
\hline \multicolumn{3}{|l|}{ (Ref:Rural) } \\
\hline Urban & .004948 & .0115053 \\
\hline \multicolumn{3}{|l|}{ Religion (Ref: Traditional) } \\
\hline Christian & -.0117256 & -.0117584 \\
\hline Islam & -.0077923 & -.0194669 \\
\hline \multicolumn{3}{|l|}{ Ethnicity(Ref: other) } \\
\hline Akan & .0325189 & .0413264 \\
\hline $\mathrm{Ga} /$ Dangme & $.0927922 *$ & .0581719 \\
\hline Ewe & .02626 & .0475367 \\
\hline Guan & .0891711 & .1010645 \\
\hline Mole-Dagbani & .0435515 & .064644 \\
\hline Grusi & .0765978 & .0744958 \\
\hline Gurma & -.042383 & -.0508447 \\
\hline Mande & .001846 & .0572815 \\
\hline \multicolumn{3}{|l|}{ Mother's Education (Ref: } \\
\hline \multicolumn{3}{|l|}{ Uneducated) } \\
\hline Primary & .0061638 & .0041942 \\
\hline Secondary & .0251717 & .0268749 \\
\hline Higher & -.0043353 & .0220255 \\
\hline \multicolumn{3}{|l|}{ Mother's Insurance (Ref: } \\
\hline \multicolumn{3}{|l|}{ Uninsured) } \\
\hline Insured & .0057376 & .0053282 \\
\hline \multicolumn{3}{|l|}{ Marital Status (Ref: Single } \\
\hline \multicolumn{3}{|l|}{ Mothers) } \\
\hline Married & .0149204 & $.0264068^{*}$ \\
\hline \multicolumn{3}{|l|}{$\begin{array}{l}\text { Mother's Employment } \\
\text { (Ref: Unemployed) }\end{array}$} \\
\hline Employed & $.0552362 * * *$ & $.0532738 * * *$ \\
\hline \multirow{2}{*}{\multicolumn{3}{|c|}{$\begin{array}{l}\text { Permission to Seek Medical } \\
\text { Care by Mother (Ref: Not a } \\
\text { big problem) }\end{array}$}} \\
\hline & & \\
\hline Big Problem & -.0092317 & .0008438 \\
\hline Money to Seek Medical & & \\
\hline
\end{tabular}

\begin{tabular}{lll}
\hline $\begin{array}{l}\text { Care by Mother (Ref: Not a } \\
\text { big problem) }\end{array}$ & & \\
$\begin{array}{l}\text { Big Problem } \\
\text { Distance to Seek Medical } \\
\text { Care by Mother (Ref: Not a } \\
\text { big problem) }\end{array}$ & -.018634 & .0002505 \\
$\begin{array}{l}\text { Big Problem } \\
\text { Partner's Education (Ref: }\end{array}$ & .0067182 & .0102996 \\
$\begin{array}{l}\text { Uneducated) } \\
\text { Primary }\end{array}$ & .0017607 & .0048402 \\
$\begin{array}{l}\text { Secondary } \\
\text { Higher }\end{array}$ & .0061579 & .0139371 \\
$\begin{array}{l}\text { Sex of Household head } \\
\text { (Ref: Female Head) }\end{array}$ & $.0492748^{*}$ & .0273523 \\
$\begin{array}{l}\text { Male head } \\
\text { Sex of Child (Ref: Female) }\end{array}$ & $-.0289405 *$ & \\
$\begin{array}{l}\text { Male Child } \\
\text { Wealth (Ref: Non-Rich) }\end{array}$ & -.0069526 & $-.0357573 * *$ \\
$\begin{array}{l}\text { Rich } \\
\text { Mother's Age }\end{array}$ & .0171771 & -.0015789 \\
$\begin{array}{l}\text { Age of Household Head } \\
\text { Birth Order of Child } \\
\text { Childs Age }\end{array}$ & -.0004006 & .0137691 \\
& -.0004467 & .0005972 \\
& -.0017044 & -.0007087 \\
& N=5066 & $-.1400591 * * *$ \\
& Prob>chi2 $=.0000$ & Prob>chi2 $=.0000$ \\
\hline
\end{tabular}

Source: Authors computation from the children's recode file, 2014 GDHS Notes: ***P-value<.01, **P-value<.05, *P-value<.1

On the determinants of demand for Rotavirus 1 vaccine as shown in Table 4, the results revealed that, on average, children from the Greater Accra, Central, Volta, Brong Ahafo, Eastern and Upper East regions were respectively 19\%, 7\%, 12\%, 24\%, $11 \%$ and $12 \%$ more likely, to have received the Rotavirus 1 vaccine as compared with their counterparts in the Upper West region. Signifying that, mothers in this region were more probable to demand for the rotavirus 1 vaccine for children relative to those in the Upper West region. Also children from $\mathrm{Ga} /$ Dangme ethnicity were 9\% more likely to have received or demanded the Rota virus 1 vaccine as compared with children from the other ethnic groups. Also employed mothers were on the average, $6 \%$ more likely to demand the Rotavirus 1 vaccine for their children as compared to the unemployed mothers. This is similar to the findings under all the doses of the Pneumococcal vaccine and hence the explanation given still holds.

In addition children whose mothers had partners with higher level of education were 5\% more likely to have received the Rotavirus 1 vaccine as compared with those children whose mothers had uneducated partners. This means partner's education plays a great role in demanding for the Rotavirus 1 vaccine for children. The AME of male household head of -.0289405 (significant at 10\%), implied that on average, children with male household heads on the average were $3 \%$ less likely to have received the Rotavirus 1 vaccine as compared with children with female household heads. Finally on rota virus 1, on average, an increase in a child's age by a year, decreased the likelihood of demanding the Rotavirus 1 vaccine by $14 \%$. This could be that since the rotavirus vaccine was introduced in 2012, older children might have been old enough to receive the $1^{\text {st }}$ dose at the recommended age of 6 weeks and hence mothers did not utilise for them.

On the determinants of demand for the Rotavirus 2 vaccine as shown in Table 4, the results revealed that, on average, children from the Volta, Greater Accra, Brong Ahafo, Eastern and Upper East regions were respectively $10 \%, 20 \%, 26 \%, 10 \%$, and $12 \%$ more likely, to have received the Rotavirus 2 vaccine as compared with their counterparts in the Upper West region. Also, on average, children with married and employed mothers were $3 \%$ and $5 \%$ respectively more likely to have received the Rotavirus 2 vaccine as compared with children with single and unemployed mothers respectively. Thus being a married or employed mother, increased the demand for the rotavirus 2 vaccine for children in 
Ghana. This is similar to the findings under the pneumococcal 2 and 3 vaccines and hence the reason given above is applicable here. In addition, children with male household heads on the average were $4 \%$ less likely to have received the Rotavirus 2 vaccine as compared with children with female household heads and hence similar to the result on Rotavirus 1 vaccine. This is very worrying given that most households are headed by males in Ghana. Thus it could be that since mothers/ females are those who normally utilise health on behalf of children, when they are heads of the family, they will be aware of the existence of vaccines and hence better utilise them for children relative to their male counterparts.

Finally on average, an increase in a child's age by a year decreased the likelihood of demanding the Rotavirus 2 vaccine by $13 \%$. This could be that since the rotavirus vaccine was introduced in 2012, older children might have been old enough to receive the $2^{\text {nd }}$ dose at the recommended age of 14 weeks and hence mothers did not utilise for them.

\section{Conclusion}

With regards to the determinants of demand for the Pneumococcal vaccines among children in Ghana, the study can conclude that, Region, Child's age and Mother's employment are the factors that determine the demand for the Pneumococcal vaccine irrespective of the dose. In addition, it can be concluded that, ethnicity, Region, mother's employment, mother's marital status, and child's age are the determinants of demand for both the $2^{\text {nd }}$ and $3^{\text {rd }}$ doses of the Pneumococcal vaccines among children in Ghana with age of the household head, Partner's level of education and mother's age being determinants of demand for only the $3^{\text {rd }}$ dose of the Pneumococcal vaccine among children in Ghana. On the Rotavirus vaccine, it can be concluded that, mother's employment, Region, child's age and sex of the household head are the factors that determine the demand for the Rotavirus vaccine among children in Ghana irrespective of the dose. However, the factors that determine the demand for the subsequent dose of the Rotavirus vaccine (Rotavirus 2) among children in Ghana can be concluded to be Child's age, sex of the household head, mother's marital status, Region and mother's employment.

In light of the above, affirmative action and policies that generate job opportunities for women or mothers must be instituted since employed mothers were more likely to demand for all the subsequent and initial doses of the Pneumococcal and Rotavirus vaccines for their children as compared to their unemployed counterparts. Alternatively, unemployed mothers can be targeted concerning strategies to increase demand for the subsequent and initial doses of the Pneumococcal and Rotavirus vaccines for children in Ghana.

Public education with household heads, uneducated partners and younger mothers as main targets must be embarked upon. This is because, demand for all the doses of the Rotavirus vaccine were less likely among children with male household heads and an increase in the age of the household head was associated with falling demand for the Pneumococcal 3 vaccine. Also uneducated partners were found to decrease the demand for the rotavirus 1 vaccine and Pneumococcal 3 vaccines for children as compared to partners with secondary education one hand and those with secondary and higher education on another hand respectively. In addition, since rising mothers age was associated with rising demand for the Pneumococcal 3 vaccine for children, younger mothers must be educated on the importance of the uptake of all the doses of vaccines.

Finally, empowerment of vulnerable women such as single mothers must be encouraged with regards to the health seeking behaviour of their children since children of single mothers were less likely to have received the Pneumococcal 2 and 3 and Rotavirus 2 vaccines as compared to their counterparts with married mothers. They can be aided through the social welfare department in Ghana.

\section{Acknowledgement}

The authors are thankful to the DHS team for providing access to data for the study.

\section{References}

[1] Bosu KW, Ahelegbe D, Edum-Fotwe E, Bainson AK \& Turkson KP (1997) Factors influencing attendance to immunization sessions for children in a rural district of Ghana. Acta Tropica 68, 259-267, Elsevier. http://dx.doi.org/10.1016/S0001-706X(97)00094-6.

[2] Cockcroft A, Usman UM, Nyamucherera FO, Emory H, Duke B, Umar AN \& Andersson N (2014) Why children are not vaccinated against measles: a cross-sectional study in two Nigerian States. Archives of Public Health, 72(48). Retrieved from http://www.archpublichealth.com/content/72/1/48. http://dx.doi.org/10.1186/2049-3258-72-48.

[3] Duah-Owusu M (n.d.) Social Determinants and Immunisation in Ghana: Is there an Association? Unpublished MPhil Thesis, University of Bergen research centre for health promotion and development, faculty of psychology.

[4] Dwumoh D, Essuman EE \& Afagbedzi KS (2014) Determinant of factors associated with child health outcomes and service utilization in Ghana: multiple indicator cluster survey conducted in 2011. Archives of Public Health, 72(42). Retrieved from http://www.archpublichealth.com/content/72/1/42

[5] Matthews Z \& Diamond I (1997) Child Immunisation in Ghana: The Effects of Family, Location and Social Disparity, Journal of Biosocial Science, 29(03), 327 - 343. DOI: null, Published online: 04 April 2001

[6] McGlynn KN (2012) Antenatal Care as a Determinant of Immunization, and Appropriate Care for Fever and Diarrhoea in Ghanaian Children. Unpublished MSc Thesis in Epidemiology \& Biostatistics, the School of Graduate and Postdoctoral Studies, the University of Western Ontario, London, Ontario, Canada.

[7] Grossman M (2000) The Human Capital Model. In Handbook of Health Economics, 1A, 347-408, edited by Anthony J. Culyer and Joseph P. Newhouse. Amsterdam: Elsevier.

[8] Grossman M (1999) the Human Capital Model and the Demand for Health. NBER Working Paper No. 7078.

[9] Grossman M (1972a) on the concept of health capital and the demand for health. Journal of Political Economy 80, 223-255. http://dx.doi.org/10.1086/259880.

[10] Grossman M (1972b) the Demand for Health: A Theoretical and Empirical Investigation. Columbia University Press for the National Bureau of Economic Research, New York.

[11] Ghana Health Service (n.d.). 2014 Family Health Annual Report.

[12] Ghana Statistical Service (GSS), Ghana Health Service (GHS) \& ICF International. (2015) Ghana Demographic and Health Survey 2014. Rockville, Maryland, USA: GSS, GHS, and ICF International.

[13] Ibnouf AH, Van den Borne HW \& Maarse JAM (2007) Factors influencing immunisation coverage among children under five years of age in Khartoum State, Sudan. South African Family Practice, 49(8), 14-14f. http://dx.doi.org/10.1080/20786204.2007.10873611.

[14] Lakew Y, Bekele A, \& Biadgilign S (2015) Factors influencing full immunization coverage among 12-23 months of age children in Ethiopia: evidence from the national demographic and health survey in 2011. BMC Public Health, 15(728). http://dx.doi.org/10.1186/s12889-015-2078-6.

[15] Logullo P, de Carvalho BH, Saconi R, \& Massad E (2008) Factors affecting compliance with the measles vaccination schedule in a Brazilian city, Sao Paulo. Sao Paulo’ Med J., 126(3), 166-71.

[16] Otieno AN, Nyawanda OB, Audi A, Emukule G, Lebo E, Bigogo G, Ochola R, Muthoka P, Widdowson M-A, Shay KD, Burton CD, Breiman FR, Katz AM \& Mott AJ (2014) Demographic, socioeconomic and geographic determinants of seasonal influenza vaccine uptake in rural western Kenya, 2011. Vaccine 32, 6699-6704. Retrieved from http://dx.doi.org/10.1016/j.vaccine.2013.10.089.

[17] Russo G, Miglietta A, Pezzotti P, Biguioh MR, Mayaka BG, Sobze SM, Stefanelli P, Vullo V \& Rezza G (2015) Vaccine coverage and determinants of incomplete vaccination in children aged 12 23 months in Dschang, West Region, Cameroon: a cross-sectional survey during a polio outbreak. BMC Public Health, 15(630). http://dx.doi.org/10.1186/s12889-015-2000-2.

[18] UNICEF (2012) Pneumonia and Diarrhoea: Tackling the deadliest diseases for the world's poorest children. Three United Nations Plaza, New York, NY 10017 USA. 
[19] UNICEF/WHO (2009) Diarrhoea: Why Children are still dying and what can be done.

[20] UN (2015) the Millennium Development Goals Report 2015.

[21] UNDP \& GOG/NDPA (2015) 2015 Ghana Millennium Development Goals report.

[22] Williams, R. (2012). Using the margins command to estimate and interpret adjusted predictions and marginal effects. The Stata Journal, 12(2), 308-331. 